\title{
Cationic Copolymerization of Tetrahydrofuran with Propylene Oxide. VII. Effect of Water on the Reaction
}

\author{
Louis-Philippe Blanchard, Jean-Claude Asselin, ${ }^{*}$ \\ and Shadi Lal MAlhotra \\ Département de Génie Chimique, Faculté des Sciences et de Génie \\ Université Laval, Québec, Qué., Canada.
}

(Received September 28, 1974)

\begin{abstract}
Propylene oxide (PO) and tetrahydrofuran (THF) were copolymerized at $0^{\circ} \mathrm{C}$ using boron trifluoride etherate as catalyst, water as cocatalyst, and ethylene dichloride as solvent. The initial rates of consumption of PO and THF were found to vary as follows with the initial catalyst, cocatalyst, and comonomer concentrations:

and

$$
-\frac{\mathrm{d}[\mathrm{THF}]_{0}}{\mathrm{~d} \theta} \propto[\text { cat. }]_{0}^{1.3}[\text { water }]_{0}^{0.3} \text { to } 0.6[\mathrm{PO}]_{0}-0.5[\mathrm{THF}]_{0}^{0.3}
$$

$$
-\frac{\mathrm{d}[\mathrm{PO}]_{0}}{\mathrm{~d} \theta} \propto[\text { cat. }]_{0}^{1.3}[\text { water }]_{0}^{0.3} \text { to } 0.6[\mathrm{PO}]_{0}^{0.8}[\mathrm{THF}]_{0}-0.4
$$

Computations of reactivity ratios yielded values of 0.26 for $\mathrm{PO}\left[\mathrm{M}_{1}\right]$ and 0.80 for THF $\left[\mathrm{M}_{2}\right]$ when the initial PO to THF molar ratio was greater than one, suggesting the formation of copolymer rich in alternating species. When the same ratio was less than one, the reactivity-ratio values increased to 1.96 for PO and 2.40 for THF, suggesting the formation of both homopolymers and copolymer from the comonomer mixture. Molecular weights of the reaction products varied from 283 to 1420 . The unusually low values are attributed to the presence of water and to transfer reactions which are believed to terminate propagation chains at an early stage.

KEY WORDS Cationic Copolymerization / Kinetics / Tetrahydrofuran / Propylene Oxide / Borontrifluoride Etherate / Water /
\end{abstract}

The copolymerization of tetrahydrofuran (THF) with alkylene oxides $^{1-4}$ has been the object of much interest, though the mechanism of the reaction remains the subject of much speculation. Extensive studies have been carried out in this laboratory, ${ }^{5-11}$ using catalysts such as: $\mathrm{BF}_{3}\left(\mathrm{C}_{2} \mathrm{H}_{5}\right)_{2} \mathrm{O}, \mathrm{SbCl}_{5}$, and $\left(\mathrm{C}_{6} \mathrm{H}_{5}\right)_{3} \mathrm{C}^{+} \mathrm{PF}_{6}{ }^{-}$, and cocatalysts such as: the diols and triols of ethane, propane, butane, and pentane, which served primarily to control the reactivity of the comonomers. The results obtained in these studies showed that the reactivity ratio of propylene oxide (PO) was higher than that of THF. More recently, the reverse has been found to be true in the copolymerization of these comonomers with the boron trifluoride etherate-glycol catalyst-cocatalyst system. ${ }^{12}$

\footnotetext{
* Present address: Crown Diamond Paints Ltd., 41 Bates Road, Outremont, Qué., Canada.
}

Similar results have been obtained with triphenylmethyl hexafluorophosphate. ${ }^{13}$ As for the reactivity ratios of the two comonomers, similar values have been found during their copolymerization in ethylene dichloride. The results of these studies are the subject of the present communication.

\section{EXPERIMENTAL}

\section{Materials}

The propylene oxide was stirred at room temperature with calcium hydride for a period of 4 to $6 \mathrm{hr}$ under dry nitrogen, then refluxed overnight. Subsequently, it was distilled on a column and the middle cut, with bp between 34 and $35^{\circ} \mathrm{C}$, was collected and stored under nitrogen in brown glass bottles which were kept in a dry box. 
The tetrahydrofuran and ethylene dichloride (EC) were purified and stored in a similar manner, while the boron trifluoride diethyl ether obtained from the Eastman Organic Company in the U.S.A. was used as such without further purification.

Bidistilled water was used for cocatalytic purposes.

\section{Experimental Procedure}

As the components of the reaction mixture, notably $\mathrm{PO}$, are hygroscopic in nature, it was necessary to carry out the reactions in a closed reactor system. Furthermore, as the cationic copolymerization of THF with PO is a highly exothermic reaction, it was necessary to insert a cooling coil in the reactor to maintain the temperature of the mixture at $0 \pm 0.1^{\circ} \mathrm{C}$. All of the polymerizations were carried out at this temperature. The reactor, shown schematically in Figure 1, was made of a $1-l$ cylindrical pyrex vessel with a hemispherical bottom, closed at the top with a stainless steel plate bearing six openings for the following accessories: thermometer, cooling coil, stirrer, thermistor detector, dry nitrogen assembly, and syringe for the injection of components and the removal of samples. The flow of coolant to the cooling coil was controlled by a model $410 \mathrm{~J}$ YSI

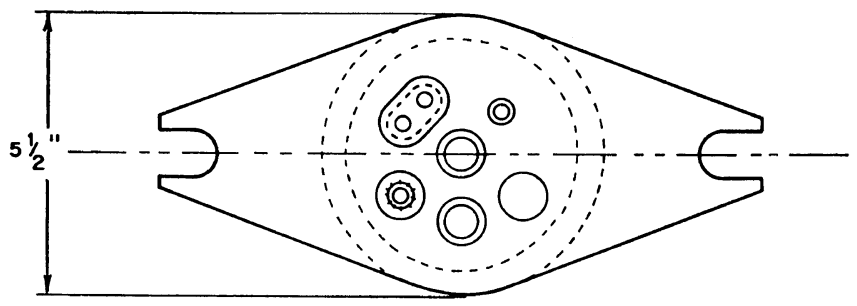

(a)

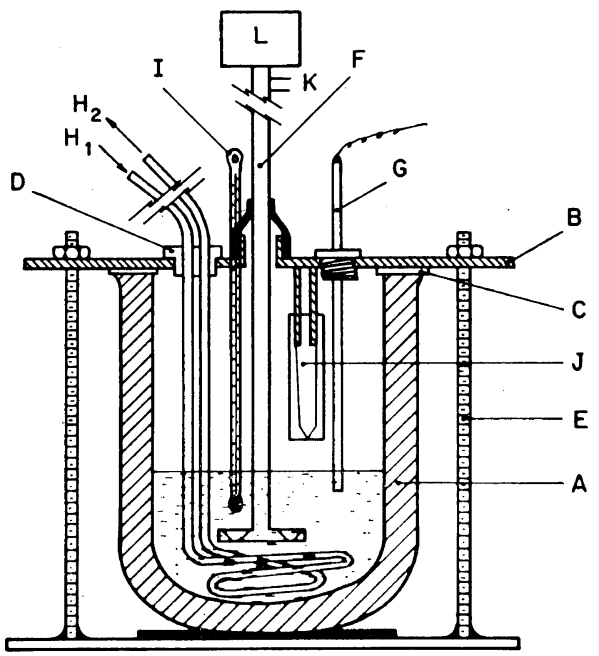

(b)

Figure 1. Schematic diagram of the reactor used for the polymerization reactions. a) top view of the cover plate; b) cutaway view of the reactor and its accessories: A, 1-l thick-wall pyrex glass vessel; B, stainless steel reactor cover; $C$, polytetrafluoroethylene sealing ring; D, PTFE cooling circuit adapter plug; E, support rods; F, hollow tube stirring rod; G, thermistor detector; $\mathrm{H}_{1}$ and $\mathrm{H}_{2}$, cooling coil inlet and outlet; $\mathrm{I}$, thermometer; $\mathrm{J}$, sampling orifice (through conically drilled PTFE sleeve); $\mathrm{K}$, dry pure nitrogen purge inlet; L, stirrer vibromotor. 
thermistor which transmitted appropriate signals to a model 63RB YSI electromagnetic valve controller. Furthermore, the reactor was placed in an ice bath to minimize heat effects from the surroundings.

Solvent (EC), comonomers (THF and PO), cocatalyst (water), and catalyst $\left(\mathrm{BF}_{3}\left(\mathrm{C}_{2} \mathrm{H}_{5}\right)_{2} \mathrm{O}\right)$ were blended in known proportions and in this order in the reaction vessel. After the injection of the catalyst, $10-\mu l$ samples were withdrawn at regular intervals and analyzed by vapor phase chromatography. The disappearance of both monomers was followed during a 5-hr period after which the reactions were stopped by the addition of an excess amount of methanol. The volatile residual components, including the solvent, were evaporated at room temperature under reduced pressure. In order to recover the copolymerization products, the residue was dissolved in benzene and then filtered, since the

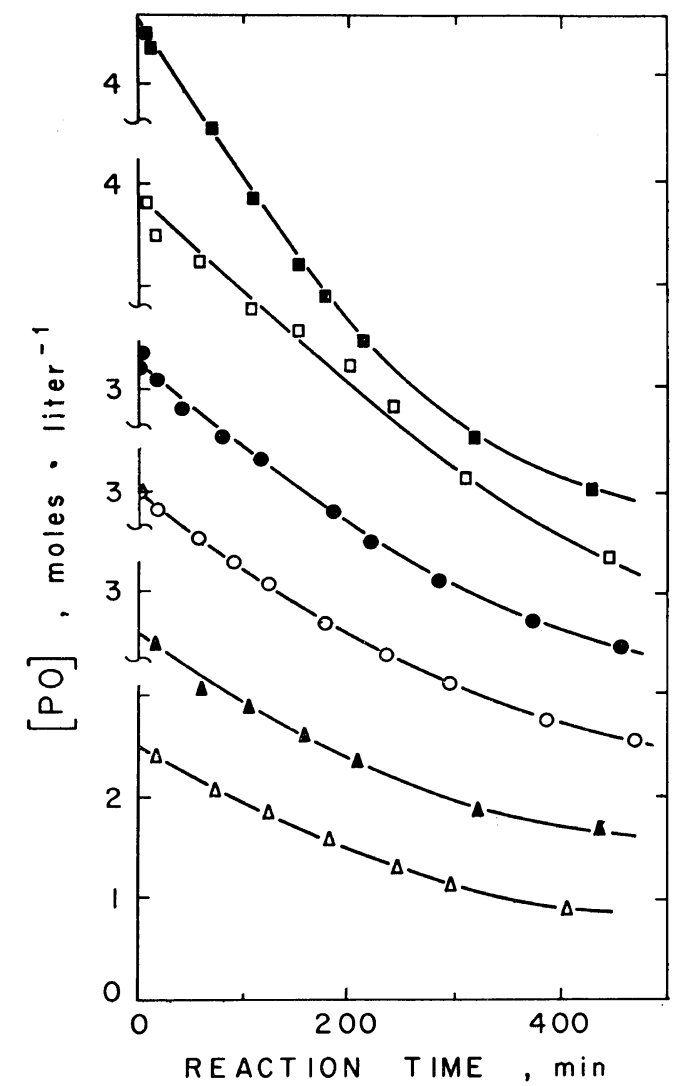

precipitated catalyst did not dissolve in benzene. The filtrate was evaporated under reduced pressure at room temperature and the final residue was dried to constant weight in a vacuum oven maintained at $35^{\circ} \mathrm{C}$.

\section{Determination of Monomer Concentrations}

The vapor fractometer used to analyze the reactor samples (a Perkin-Elmer model 154-C) was equipped with an electronic integrator to obtain quantitative estimates of the monomer concentrations. The volatile components were separated on a UCON polyglycol LB-550-X type $\mathrm{R}$ column with helium as the carrier gas flowing at a rate of $100 \mathrm{~m} l \mathrm{~min}^{-1}$. Calibration plots, involving peak area $v s$. moles of substance injected, were linear over a wide range and passed through the origin.

\section{Determination of Water Concentrations}

The water content in each reaction mixture

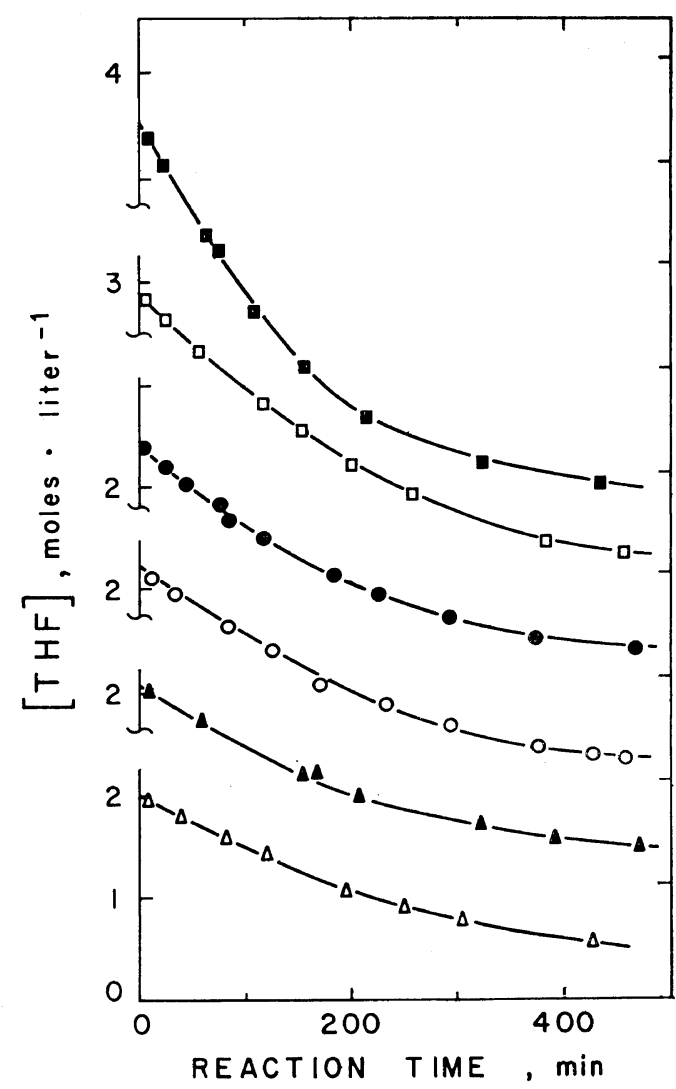

Figure 2. Concentration vs. time curves for $\mathrm{PO}$ and THF at various initial solvent to comonomer molar ratios: $\triangle$, A-1; $\Delta$, A-2; $\bigcirc$, A-3; ๑, A-4; $\square$, A-5;, A-6 (see Table I). 
Cationic Copolymerization of Tetrahydrofuran with Propylene Oxide. VII.

was determined by Karl-Fischer titrations carried out with an automatic titrimeter (Radiometer, model TTTIC) equipped with platinum electrodes capable of circulating a current of $10 \mu \mathrm{A}$. Karl-Fischer reagent, a mixture of iodides, oxides of sulphur, pyridine and methanol, is added continuously until the inflection point is reached. Prior to making a water determination, the Karl-Fischer reagent was standardized by titrating known quantities of water.

\section{Determination of Molecular Weights}

Number-average molecular weights $\bar{M}_{n}$ of the recovered copolymerization products were determined with a Mechrolab vapor-pressure osmometer (model $301 \mathrm{~A}$ ) operated at $37^{\circ} \mathrm{C}$ with methyl ethyl ketone as solvent. The calibration constant of the instrument, $440 \Omega \mathrm{mol}^{-1} l^{-1}$, was established with substances of known molecular weights, such as: polypropylene glycols (POPG 4025 and 2025), polyethylene glycols (POEG 200,600, and 1000), and benzil (210).

\section{RESULTS AND DISCUSSION}

The concentrations of $\mathrm{PO}$ and THF in mixtures containing various amounts of solvent have been plotted against reaction time in Figure 2. The data derived from these curves shows that, as the EC content is decreased, the initial rates of comonomer consumption increase, as do, for that matter, the molecular weights of the copolymerization products (see Table I). This is as might be expected, since the overall comonomer concentrations increase as the amount of solvent is decreased, bringing about an increase in the rates of monomer consumption. The molecular weights of the products show a similar trend, although the absolute values are low when compared to those obtained from theoretical calculations where it is assumed that the number of moles of catalyst fix the number of moles of product. The lowering of the molecular weights with increasing quantities of solvent suggests that ethylene dichloride participates in some manner in the mechanism responsible for the termination of propagating chains. Chain transfer could definitely be attributed to the solvent if chlorides were found in the products, but such was not the case. Transfer reactions must therefore come from some other source, such as chain "back-biting". It is not unlikely that an even lower EC content would prove more effective in reducing polymer deterioration from side reactions and thereby increase the molecular weights; however, the importance of using a solvent cannot be overstressed if control of the temperature of the medium is to be assured during the initial stages of the reaction when the catalyst is being added and if the viscosity of the medium is to be reduced in the later stages as the reaction progresses. These parameters would both increase unduly if the ratio of solvent to comonomers were smaller, let alone reduced to zero. Mixing of the reactants would no longer yield homogeneous solutions. It is for this reason that the solvent to comonomer molar ratio was arbitrarily fixed at a practical working value of 0.57 .

Table I. Influence of the solvent to comonomer molar ratio on the initial rates of comonomer consumption at $0^{\circ} \mathrm{C}^{\mathrm{a}}$

\begin{tabular}{|c|c|c|c|c|c|c|c|c|}
\hline \multirow[t]{2}{*}{ No. } & \multirow{2}{*}{$\begin{array}{l}\text { Total } \\
\text { volume, } \\
\mathrm{m} l\end{array}$} & \multirow{2}{*}{$\underset{\mathrm{mol}}{(\mathrm{EC})_{0}}$} & \multirow{2}{*}{$\begin{array}{l}\mathrm{C})_{0} /(\mathrm{PO}+\mathrm{THF}) \\
\text { molar ratio }\end{array}$} & \multirow{2}{*}{$\begin{array}{c}\left(-\mathrm{d}[\mathrm{PO}]_{0} / \mathrm{d} \theta\right) 10^{2} \\
\operatorname{mol~} l^{-1} \min ^{-1}\end{array}$} & \multirow{2}{*}{$\begin{array}{l}\left.-\mathrm{d}[\mathrm{THF}]_{0} / \mathrm{d} \theta\right) 10^{2}, \\
\mathrm{~mol}^{-1} \mathrm{~min}^{-1}\end{array}$} & \multicolumn{2}{|c|}{$\begin{array}{l}\% \text { conversion } \\
\text { at } 300 \mathrm{~min}\end{array}$} & \multirow{2}{*}{$\begin{array}{l}\text { Molecular weight } \\
\text { of the final } \\
\text { products, } \\
\bar{M}_{n}(\text { VPO })\end{array}$} \\
\hline & & & & & & PO & THF & \\
\hline A-1 & 415 & 3.45 & 1.85 & 0.55 & 0.52 & 60.5 & 64.8 & 860 \\
\hline A-2 & 400 & 3.28 & 1.76 & 0.68 & 0.60 & 61.5 & 66.4 & 880 \\
\hline A-3 & 345 & 2.57 & 1.38 & 0.76 & 0.65 & 60.9 & 65.9 & 890 \\
\hline A-4 & 305 & 2.11 & 1.13 & 0.89 & 0.77 & 63.8 & 68.7 & 1169 \\
\hline A-5 & 265 & 1.61 & 0.86 & 0.93 & 0.93 & 66.3 & 70.6 & 1420 \\
\hline A-6 & 225 & 1.07 & 0.57 & 1.56 & 1.67 & 79.4 & 86.6 & 1418 \\
\hline
\end{tabular}

a Other conditions: $(\mathrm{PO})_{0}, 1.03 \mathrm{~mol}$; (THF) $)_{0}, 0.83 \mathrm{~mol}$; (catalyst) $)_{0}, 4.8 \times 10^{-3} \mathrm{~mol}$; (water $)_{0}, 9.6 \times 10^{-3} \mathrm{~mol}$. 
The concentrations of $\mathrm{PO}$ and THF with time, in mixtures containing various initial catalyst concentrations, have been plotted in Figure 3.
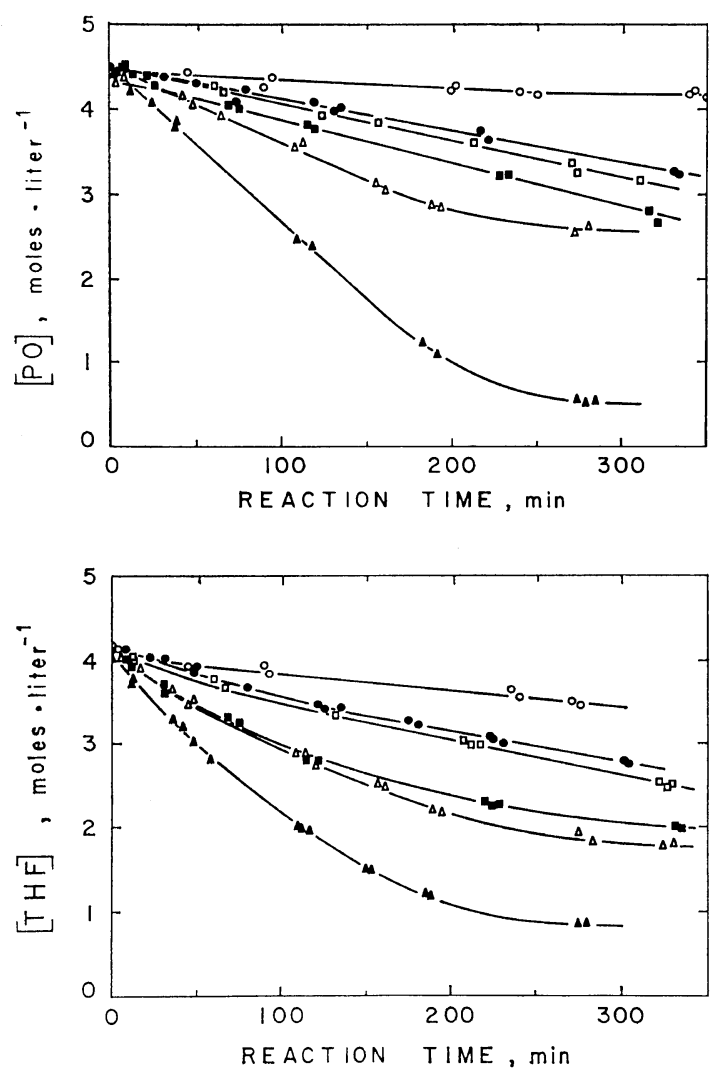

Figure 3. Concentration vs. time curves for PO and THF at various initial catalyst concentrations: $\bigcirc$, В-1; ○, В-2; $\square$, B-3; $\square$, B-4; $\triangle$, B-5; $\Delta$, B-6 (see Table II).
From the slopes of the curves, the initial rates of comonomer consumption are seen to increase regularly with catalyst concentration. This is believed to be due to a corresponding increase in the number of active reaction centers. The molecular weights of the products, however, remain essentially constant, although a slightly higher value is noted at a [water $]_{0}$ to [cat.] ratio of 2.0 (see Table II). With a given amount of comonomers one would normally expect $\bar{M}_{n}$ to decrease with an increasing number of active centers; however, with a nearly constant

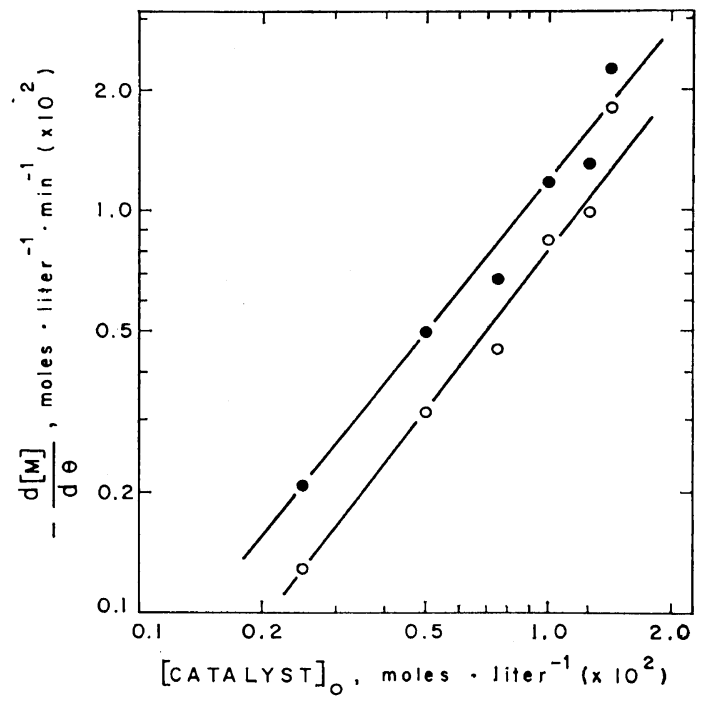

Figure 4. Log-log plots of the initial rates of comonomer consumption as a function of the initial catalyst concentration:, $\mathrm{d}[\mathrm{THF}]_{0} / \mathrm{d} \theta$; $O, \mathrm{~d}[\mathrm{PO}]_{0} / \mathrm{d} \theta$.

Table II. Influence of the initial catalyst concentration on the initial rates of comonomer consumption at $0^{\circ} \mathrm{C}^{\mathrm{a}}$

\begin{tabular}{|c|c|c|c|c|c|c|c|}
\hline \multirow[t]{2}{*}{ No. } & \multirow{2}{*}{$\begin{array}{c}\text { [catalyst] }]_{0} \times \\
10^{2} \\
\operatorname{mol}^{-1}\end{array}$} & \multirow[t]{2}{*}{$\begin{array}{c}\left(-\mathrm{d}[\mathrm{PO}]_{0} / \mathrm{d} \theta\right) 10^{2} \\
\operatorname{mol} l^{-1} \mathrm{~min}^{-1}\end{array}$} & \multirow[t]{2}{*}{$\underset{\left.\mathrm{mol} \mathrm{l}^{-1}\right]_{\mathrm{min}}^{-1}}{(-\mathrm{d}[\mathrm{THF}] / \mathrm{d} \theta) 10^{2}}$} & \multicolumn{2}{|c|}{$\begin{array}{c}\text { Concentration } \\
\text { changes at } 300 \mathrm{~min}, \\
\text { mol } l^{-1}\end{array}$} & \multirow[t]{2}{*}{$\begin{array}{c}(\Delta[\mathrm{PO}]+\Delta[\mathrm{THF}]) / \\
{[\text { cat. }]_{0}, \times 10^{2}}\end{array}$} & \multirow{2}{*}{$\begin{array}{c}\text { Molecular weight } \\
\text { of the final } \\
\text { products, } \\
\bar{M}_{n} \text { (VPO) }\end{array}$} \\
\hline & & & & $\Delta[\mathrm{PO}]$ & $\Delta[\mathrm{THF}]$ & & \\
\hline B-1 & 0.25 & 0.13 & 0.21 & 0.23 & 0.67 & 3.6 & 756 \\
\hline B-2 & 0.51 & 0.32 & 0.50 & 1.11 & 0.95 & 4.0 & 1005 \\
\hline B-3 & 0.75 & 0.46 & 0.68 & 1.29 & 1.49 & 3.7 & 734 \\
\hline B-4 & 1.01 & 0.85 & 1.18 & 1.63 & 2.03 & 3.6 & 896 \\
\hline B-5 & 1.26 & 1.00 & 1.30 & 1.84 & 2.29 & 3.3 & 785 \\
\hline B-6 & 1.52 & 1.82 & 2.25 & 3.99 & 3.25 & 4.8 & 934 \\
\hline
\end{tabular}

a Other conditions: $[\mathrm{PO}]_{0}, 4.48 \mathrm{~mol} l^{-1} ;[\mathrm{THF}]_{0}, 4.08 \mathrm{~mol} l^{-1} ;[\text { water }]_{0}, 1.0 \times 10^{-2} \mathrm{~mol} l^{-1} ;[\mathrm{EC}]_{0}, 4.88 \mathrm{~mol} l^{-1}$. 
Cationic Copolymerization of Tetrahydrofuran with Propylene Oxide. VII.

$(\Delta[\mathrm{PO}]+\Delta[\mathrm{THF}])$ to $[\mathrm{cat} .]_{0}$ molar ratio, the molecular weights of the reaction products do not vary unduly.

In Figure 4 are shown $\log -\log$ plots of the initial rates of comonomer consumption as a function of the catalyst concentration, from which the following expressions were obtained:

$$
-\frac{\mathrm{d}[\mathrm{PO}]_{0}}{\mathrm{~d} \theta}=3.2[\mathrm{cat} .]_{0}{ }^{1.3}
$$

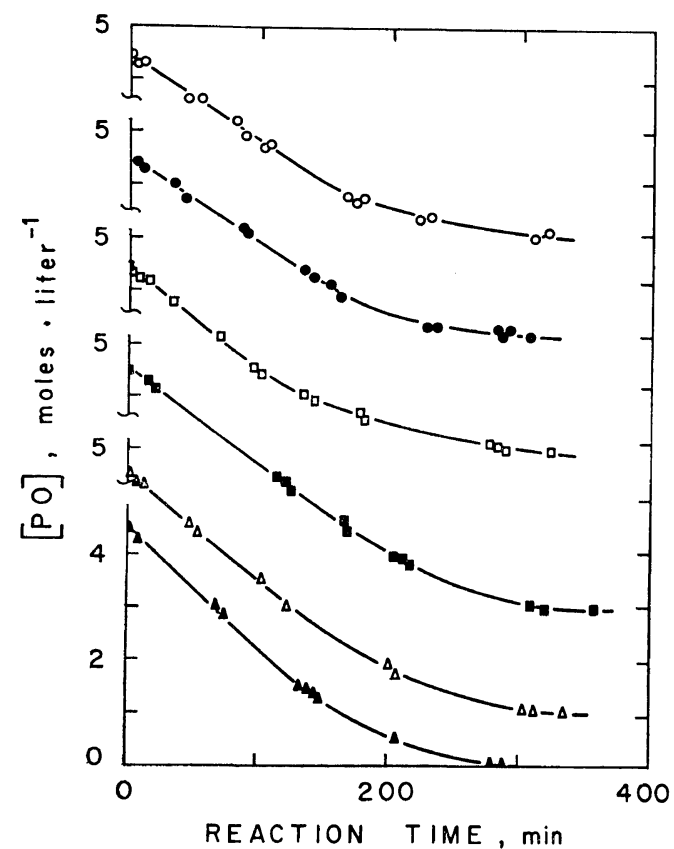

$$
-\frac{\mathrm{d}[\mathrm{THF}]_{0}}{\mathrm{~d} \theta}=4.9[\mathrm{cat} .]_{0}^{1.3}
$$

Clearly, the initial rates of comonomer consumption with respect to the initial catalyst concentration obey a 1.3 order law.

The PO and THF concentrations in mixtures containing various initial amounts of cocatalyst (water) have been plotted against time in Figure 5. The data obtained from these curves, along

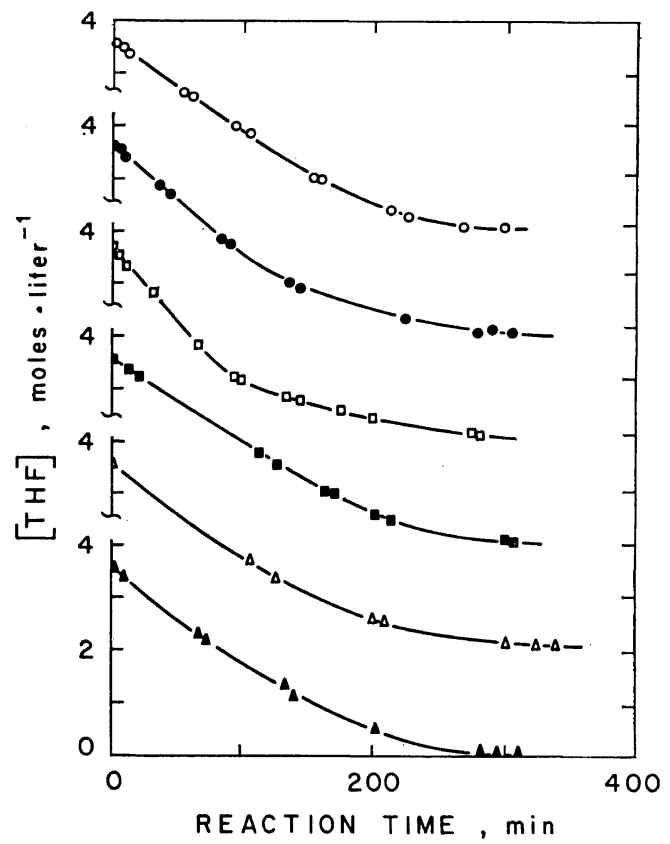

Figure 5. Concentration vs. time curves for $P O$ and THF at various initial water concentrations: $\mathrm{O}, \mathrm{C}-1 ; \bullet, \mathrm{C}-2 ; \square, \mathrm{C}-3 ; \mathbf{\square}, \mathrm{C}-4 ; \triangle, \mathrm{C}-5 ; \Delta, \mathrm{C}-6$ (see Table III).

Table III. Influence of the cocatalyst (water) concentration on the initial rates

\begin{tabular}{|c|c|c|c|c|c|c|}
\hline \multirow{2}{*}{ No. } & \multirow{2}{*}{$\begin{array}{c}\text { [water }]_{0} \times 10^{2} \\
\operatorname{mol} l^{-1}\end{array}$} & \multirow{2}{*}{$\begin{array}{c}\left(-\mathrm{d}[\mathrm{PO}]_{0} / \mathrm{d} \theta\right) 10^{2} \\
\mathrm{~mol} l^{-1} \min ^{-1}\end{array}$} & \multirow{2}{*}{$\begin{array}{c}\left(-\mathrm{d}[\mathrm{THF}]_{0} / \mathrm{d} \theta\right) 10^{2} \\
\mathrm{~mol}^{-1} \mathrm{~min}^{-1}\end{array}$} & \multicolumn{2}{|c|}{$\begin{array}{l}\% \text { conversion } \\
\text { at } 300 \mathrm{~min}\end{array}$} & \multirow{2}{*}{$\begin{array}{c}\text { Molecular weight of } \\
\text { the final products, } \\
\bar{M}_{n} \text { (VPO) }\end{array}$} \\
\hline & & & & PO & THF & \\
\hline C-1 & 1.17 & 1.50 & 2.05 & 74.1 & 96.8 & 674 \\
\hline C-2 & 1.43 & 1.62 & 2.15 & 74.0 & 90.1 & 785 \\
\hline C-3 & 2.89 & 2.00 & 2.57 & 82.1 & 96.0 & 846 \\
\hline C-4 & 3.73 & 1.78 & 1.62 & 98.0 & 90.7 & 719 \\
\hline C-5 & 4.75 & 2.04 & 1.80 & 94.5 & 93.0 & 710 \\
\hline C-6 & 5.31 & 2.21 & 2.03 & 99.5 & 95.5 & 640 \\
\hline
\end{tabular}
of comonomer consumption at $0^{\circ} \mathrm{C}^{\mathrm{a}}$

a Other conditions: $[\mathrm{PO}]_{0}, 4.42 \mathrm{~mol} l^{-1} ;[\mathrm{THF}]_{0}, 3.66 \mathrm{~mol} l^{-1}$; [catalyst $]_{0}, 1.52 \times 10^{-2} \mathrm{~mol} l^{-1} ;[\mathrm{EC}]_{0}, 4.60 \mathrm{~mol}$ $l^{-1}$. 


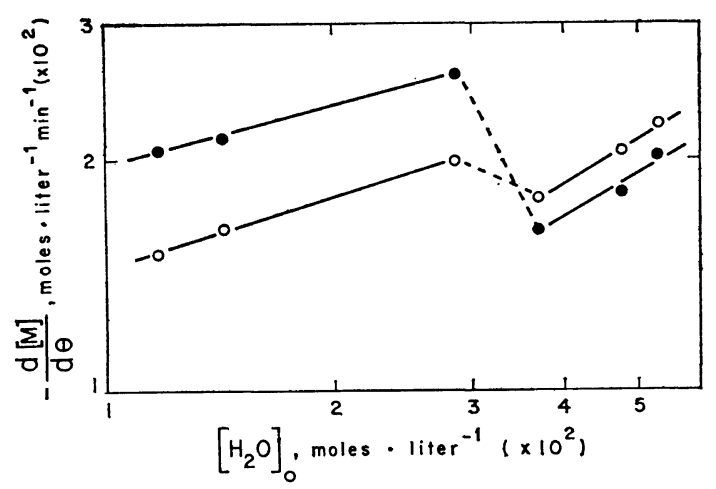

Figure 6. Log-log plots of the initial rates of comonomer consumption as a function of the initial water concentration:, $\mathrm{d}[\mathrm{THF}]_{0} / \mathrm{d} \theta ; \bigcirc$, $\mathrm{d}[\mathrm{PO}]_{0} / \mathrm{d} \theta$.

with other measurements given in Table III, show that the initial rate of $\mathrm{PO}$ and THF consumption increases with increasing initial water to catalyst concentration ratio. At a [water] $]_{0}$ to [cat.] ratio of 2.0 an unexpected drop in the initial rates of comonomer consumption is observed. Beyond this ratio, the initial rates of comonomer consumption increase once again but follow a different power law, as is shown in Figure 6 where the initial rates of PO and THF consumption have been plotted on $\log$ - $\log$ scales as a function of the initial water concentration. The rates obey variable power laws as shown in the following two equations:

$$
-\frac{\mathrm{d}[\mathrm{PO}]_{0}}{\mathrm{~d} \theta}=0.063[\text { water }]_{0}^{0.3} \text { to } 0.13[\text { water }]_{0}^{0.6}
$$

and

$$
-\frac{\mathrm{d}[\mathrm{THF}]_{0}}{\mathrm{~d} \theta}=0.058[\text { water }]_{0}{ }^{0.3} \text { to } 0.11[\text { water }]_{0}{ }^{0.6}
$$

The molecular weights of the product (see Table III) show maximum values at a [water] to [cat.] molar ratio of 2.0 , but beyond this ratio the values decrease. These observations indicate one of two things: either the number of active centers increases up to a [water $]_{0}$ to [cat.] ratio of 2.0 , beyond which it decreases due to chain termination by excess water, or that the nature of the active centers above and below a ratio of 2.0 is different.

In order to throw additional light on this topic, experiments were carried out with fixed PO and THF concentrations, but with changing catalyst and water concentrations. The results are shown in Figure 7, where the percent water conversion has been plotted against time for several initial [water $]_{0}$ to [cat.] molar ratios. The data in Table IV, based on the results obtained from Figure 7, clearly indicate that the

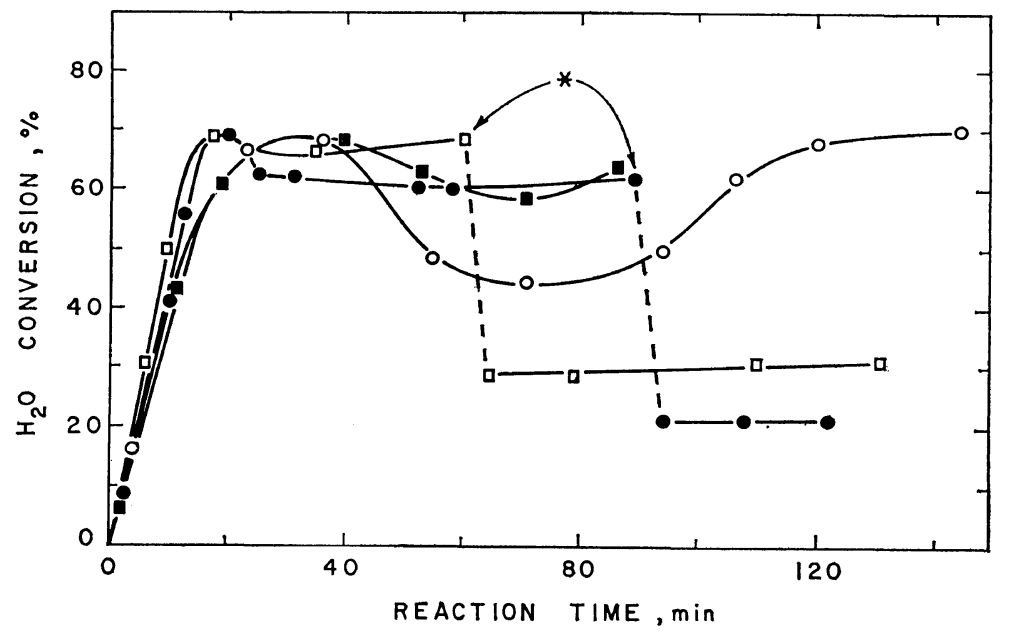

Figure 7. Conversion vs. time curves for water under various operating conditions (*, addition of water during propagation): $\square, \mathrm{D}-1 ; \mathrm{O}, \mathrm{D}-2 ; 0, \mathrm{D}-3 ; \mathbf{D}, \mathrm{D}-4$ (see Table IV). 
Cationic Copolymerization of Tetrahydrofuran with Propylene Oxide. VII.

Table IV. Effect of the water to catalyst initial concentration ratio on the rate of water consumption at $0^{\circ} \mathrm{C}$. $^{\mathrm{a}}$

\begin{tabular}{ccccc}
\hline No. & $\begin{array}{c}\text { wwater }]_{0} \times[\text { catalyst }]_{0} \times \\
10^{2}, \\
\mathrm{~mol}^{-1}\end{array}$ & $\begin{array}{c}10^{2}, \\
\mathrm{~mol} l^{-1}\end{array}$ & $\begin{array}{c}\text { [water }]_{0} / \\
{[\text { catalyst }]_{0}}\end{array}$ & $\begin{array}{c}-\mathrm{d}[\text { water }]_{0} / \\
\mathrm{d} \theta \times 10^{3}, \\
\mathrm{~mol} l^{-1} \mathrm{~min}^{-1}\end{array}$ \\
\hline D-1 & 2.46 & 1.98 & 1.24 & 1.20 \\
D-2 & 2.47 & 1.45 & 1.70 & 1.00 \\
D-3 & 4.92 & 1.98 & 2.48 & 2.10 \\
D-4 & 4.92 & 1.45 & 3.39 & 1.80
\end{tabular}

a Other conditions: $[\mathrm{THF}]_{0}, 3.61 \mathrm{~mol}^{-1} ; \quad[\mathrm{PO}]_{0}$, $4.40 \mathrm{~mol} \mathrm{l}^{-1}$.

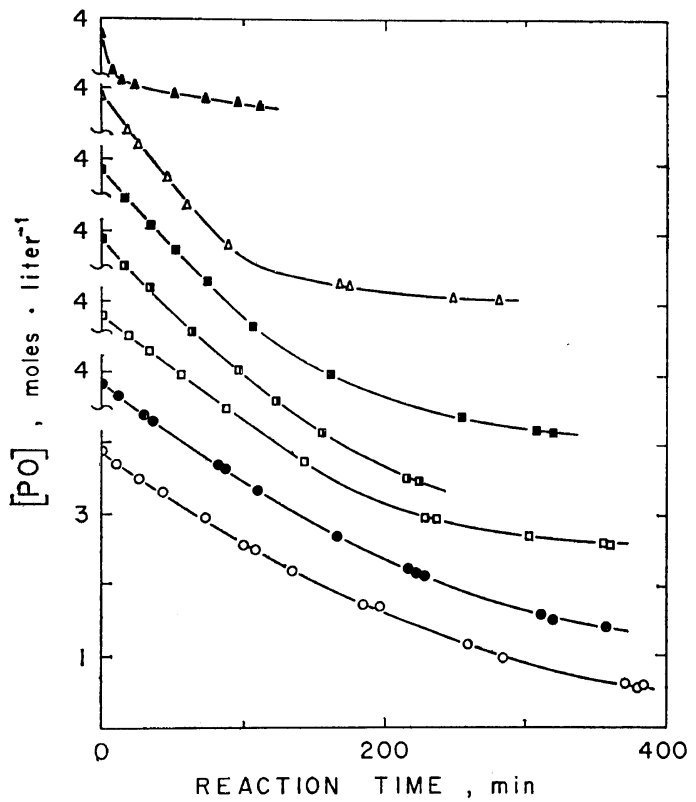

rate of initial water consumption increases with increasing [water $]_{0}$ to [cat. $]_{0}$ ratio, albeit irregularly. Furthermore, for an initial catalyst concentration and two different initial water concentrations, the rate of water consumption is higher for the higher initial water concentration. This would indicate that the catalyst forms different types of active centers on reacting with water, depending on the concentration of the latter in the solution, and that there is a critical concentration of water (at a [water] to [cat.] $]_{0}$ ratio of about 2.0) at which the

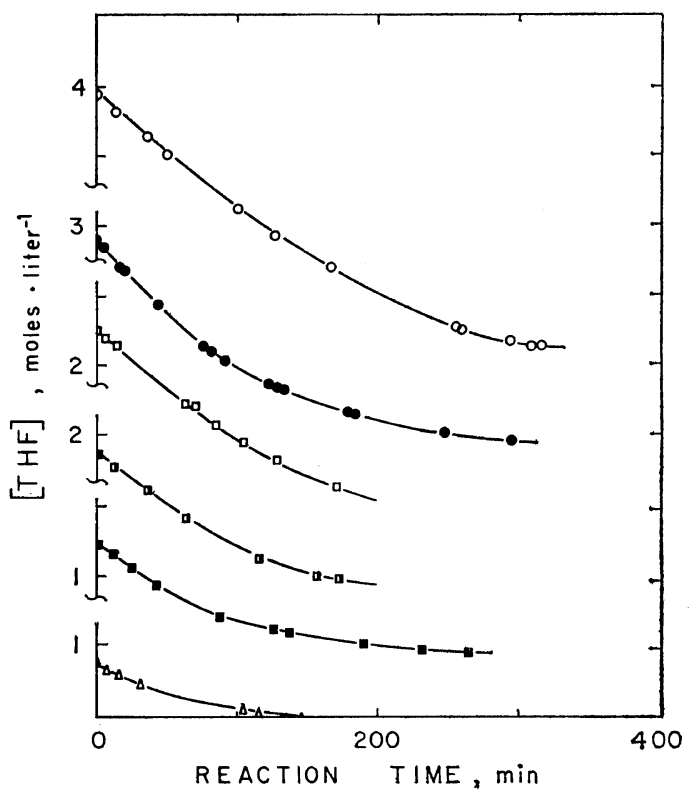

Figure 8. Concentration vs. time curves for PO and THF at various initial THF concentrations: O. E-1; ○, E-2; $\square$, E-3; $\mathbf{\square}$, E-4; $\square$, E-5; $\triangle$, E-6; $\Delta$, E-7 (see Table V).

Table V. Effect of the initial THF concentration on the initial rates of comonomer consumption at $0^{\circ} \mathrm{Ca}^{\mathrm{a}}$

\begin{tabular}{lcccccc}
\hline No. & $\begin{array}{c}{[\mathrm{THF}]_{0},} \\
\mathrm{~mol} l^{-1}\end{array}$ & $\begin{array}{c}\left.-\mathrm{d}[\mathrm{PO}]_{0} / \mathrm{d} \theta\right) 10^{2}, \\
\mathrm{~mol} l^{-1} \mathrm{~min}^{-1}\end{array}$ & $\begin{array}{c}\left.-\mathrm{d}[\mathrm{THF}]_{0} / \mathrm{d} \theta\right) 10^{2}, \\
\mathrm{~mol} l^{-1} \mathrm{~min}^{-1}\end{array}$ & $\begin{array}{c}\text { \% conversion } \\
\text { at } 300 \mathrm{~min}\end{array}$ & $\begin{array}{c}\text { Molecular weight of } \\
\text { the final products, }\end{array}$ \\
\hline E-1 & 3.90 & 1.22 & 1.80 & 76.9 & 87.5 & 817 \\
E-2 & 2.86 & 1.49 & 1.73 & 81.1 & 96.1 & 855 \\
E-3 & 2.55 & 1.47 & 1.70 & 79.0 & 96.5 & 905 \\
E-4 & 1.75 & 1.78 & 1.55 & 94.8 & 100.0 & 925 \\
E-5 & 1.53 & 1.90 & 1.43 & 92.3 & 100.0 & 967 \\
E-6 & 0.77 & 2.44 & 1.22 & 71.5 & 100.0 & 727 \\
E-7 & 0.00 & 6.08 & 0.00 & 37.7 & - & 590
\end{tabular}

a Other conditions: $[\mathrm{PO}]_{0}, 3.82 \mathrm{~mol} l^{-1}$; [catalyst $]_{0}, 1.52 \times 10^{-2} \mathrm{~mol} l^{-1} ; \quad[\text { water }]_{0}, 2.20 \times 10^{-2} \mathrm{~mol} l^{-1}$; total volume, $280 \mathrm{ml}$. 
catalyst shows its maximum efficiency. Below this concentration, all of the catalytic species are not reactive, while above it the excess water acts as a chain-terminating agent. The curves in Figure 7 show a high $(70 \%)$ initial water consumption. This consumption $(0.7 \times 0.0492$ $\left.\mathrm{mol} l^{-1}\right)$ for a fixed catalyst content $(0.0198 \mathrm{~mol}$ $\left.l^{-1}\right)$ yields a [water $]_{0}$ to [cat. $]_{0}$ ratio of 2.0 , the observed ideal complex. The remaining percentage of water $(30 \%)$ is found to increase as the reaction progresses. It is believed that this release of the water initially attached to the catalyst comes from some reversible reaction.

In order to establish with what part of the mechanism (initiation, propagation, or termination) the water is associated, a supplemental amount of water was added to mixtures during the propagation of the reaction, at the points indicated by asterisks in Figure 7. With each addition of water, its total concentration in the solution increased as expected and therefore its percent consumption (based on the new total) decreased, as shown by the dotted lines in Figure 7, and remained constant afterwards. One concludes from this that water is not consumed during the propagation step but only during the initiation and termination steps, the latter being reflected in the decrease of molecular weights with excess water.

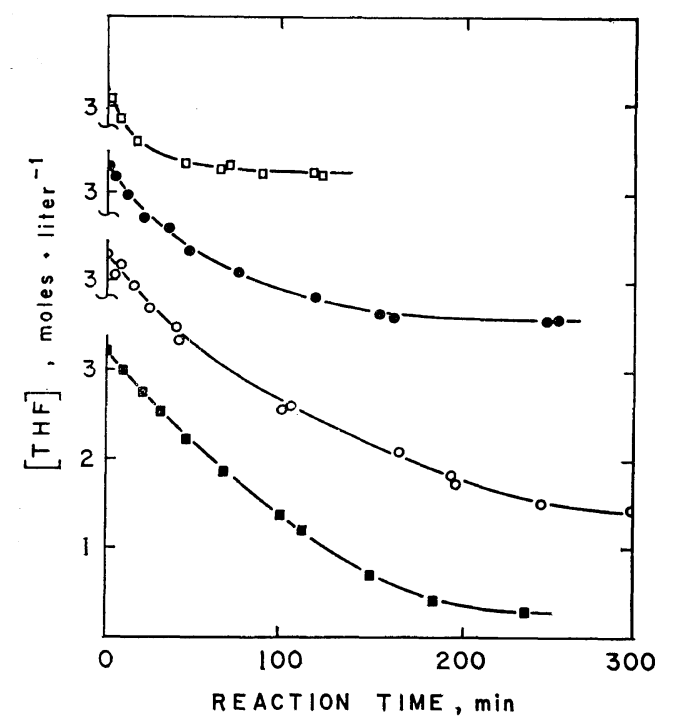

Figure 8 shows plots of PO and THF concentrations against time for mixtures containing various initial THF concentrations. Table V summarizes the rate data derived from these curves as well as other information on the percent conversions and the molecular weights. One notes that, as the initial THF concentration is decreased, its initial rate of consumption

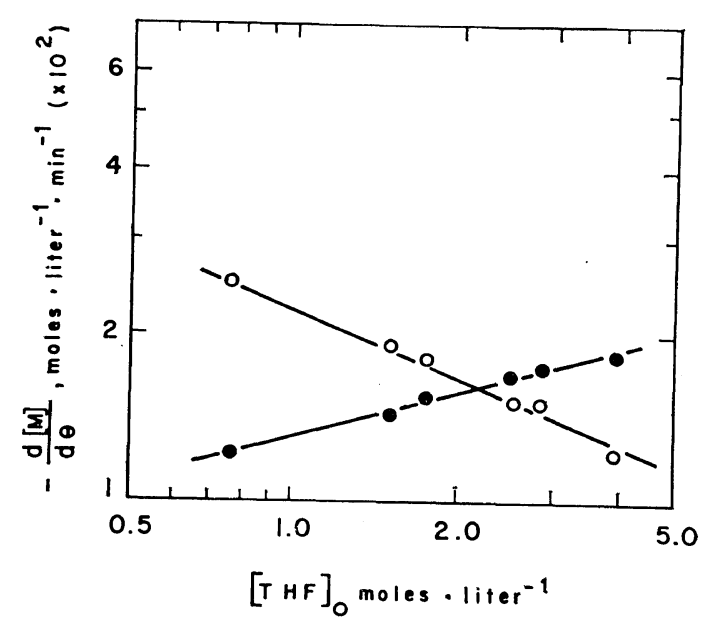

Figure 9. $\log -\log$ plots of the initial rates of comonomer consumption as a function of the initial THF concentration: $\bullet, \mathrm{d}[\mathrm{THF}]_{0} / \mathrm{d} \theta ; O$, $\mathrm{d}[\mathrm{PO}]_{0} / \mathrm{d} \theta$.

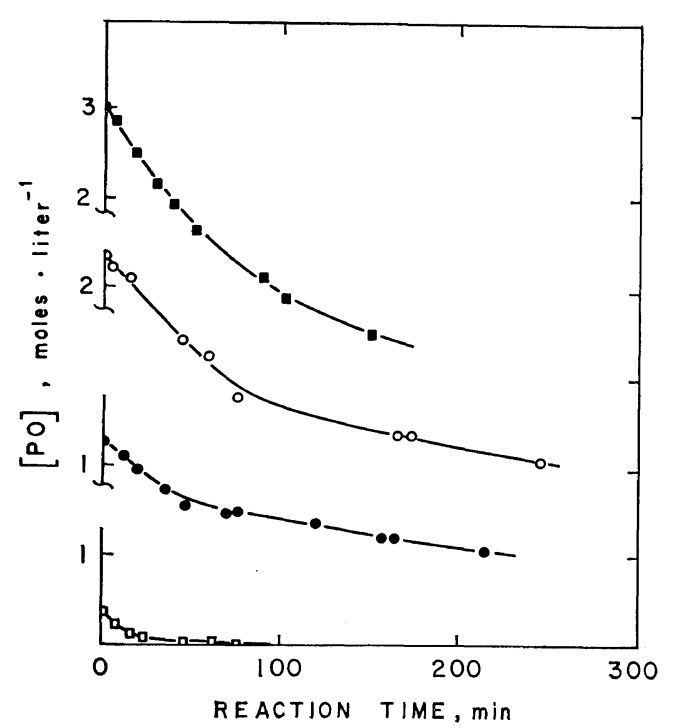

Figure 10. Concentration $v s$. time curves for PO and THF at various initial PO concentrations: 口, F-1; O, F-2; ๑, F-3; $\square$, F-4 (see Table VI). 
Cationic Copolymerization of Tetrahydrofuran with Propylene Oxide. VII.

Table VI. Influence of the initial PO concentration on the initial rates of comonomer consumption at $0^{\circ} \mathrm{C}^{\mathrm{a}}$

\begin{tabular}{lcccccc}
\hline No. & $\begin{array}{c}{[\mathrm{PO}]_{0},} \\
\mathrm{~mol} l^{-1}\end{array}$ & $\begin{array}{c}\left(-\mathrm{d}[\mathrm{PO}]_{0} / \mathrm{d} \theta\right) 10^{2}, \\
\mathrm{~mol} l^{-1} \mathrm{~min}^{-1}\end{array}$ & $\begin{array}{c}\left(-\mathrm{d}[\mathrm{THF}]_{0} / \mathrm{d} \theta\right) 10^{2} \\
\mathrm{~mol} l^{-1} \mathrm{~min}^{-1}\end{array}$ & \multicolumn{2}{c}{$\begin{array}{c}\% \text { conversion } \\
\text { at } 300 \mathrm{~min}\end{array}$} & $\begin{array}{c}\text { Molecular weight of } \\
\text { the final products, } \\
\bar{M}_{n} \text { (VPO) }\end{array}$ \\
\hline F-1 & 3.00 & 1.80 & 2.35 & 100.0 & 94.0 & 832 \\
F-2 & 2.35 & 1.50 & 2.65 & 100.0 & 87.8 & 820 \\
F-3 & 1.25 & 0.98 & 3.75 & 100.0 & 50.0 & 660 \\
F-4 & 0.39 & 0.38 & 6.50 & 100.0 & 32.3 & 283 \\
F-5 & 0.00 & - & 0.00 & - & 0.0 & - \\
\hline
\end{tabular}

a Other conditions: [THF], $3.28 \mathrm{~mol} l^{-1}$; [catalyst ], $1.52 \times 10^{-2} \mathrm{~mol} l^{-1}$; [water], $2.10 \times 10^{-2} \mathrm{~mol} l^{-1}$; total volume, $280 \mathrm{ml}$.

decreases, as might be expected; however, parallel to this, the initial rate of consumption of PO increases substantially, its percent conversion rising through a maximum value and then dropping off sharply as the initial THF concentration approaches zero. It is interesting to note that the percent conversion of THF rises to $100 \%$ as its initial concentration approaches zero and the molecular weights, like the conversion of PO, pass through a maximum value. As the mixtures become poorer in initial THF content, the products must of necessity contain longer segments of PO based chains. The possibility of the formation of PO-based homopolymers cannot therefore be ruled out per se.

In Figure 9 are shown $\log -\log$ plots of the initial rates of comonomer consumption as a function of the initial THF concentration. From the slopes of the straight lines obtained, it was possible to derive the following expressions:

$$
-\frac{\mathrm{d}[\mathrm{PO}]_{0}}{\mathrm{~d} \theta}=0.022[\mathrm{THF}]_{0}^{-0.4}
$$

and

$$
-\frac{\mathrm{d}[\mathrm{THF}]_{0}}{\mathrm{~d} \theta}=0.013[\mathrm{THF}]_{0}{ }^{0.3}
$$

Figure 10 shows plots of PO and THF concentrations against time for mixtures containing various initial PO concentrations. Table VI summarizes the data derived from the curves in Figure 10, as well as other information on the percent conversion and the molecular weights. Decreasing the initial PO concentration decreases its initial rate of consumption, while that of THF increases considerably. Figure 11 shows $\log -\log$ plots of the initial rates of comonomer consumption as a function of the initial PO concentration. From the slopes of the two lines, the following expressions were derived:

$$
-\frac{\mathrm{d}[\mathrm{PO}]_{0}}{\mathrm{~d} \theta}=0.008[\mathrm{PO}]_{0}^{0.8}
$$

and

$$
-\frac{\mathrm{d}[\mathrm{THF}]_{0}}{\mathrm{~d} \theta}=0.041[\mathrm{PO}]_{0}^{-0.5}
$$

The initial concentrations of each of the

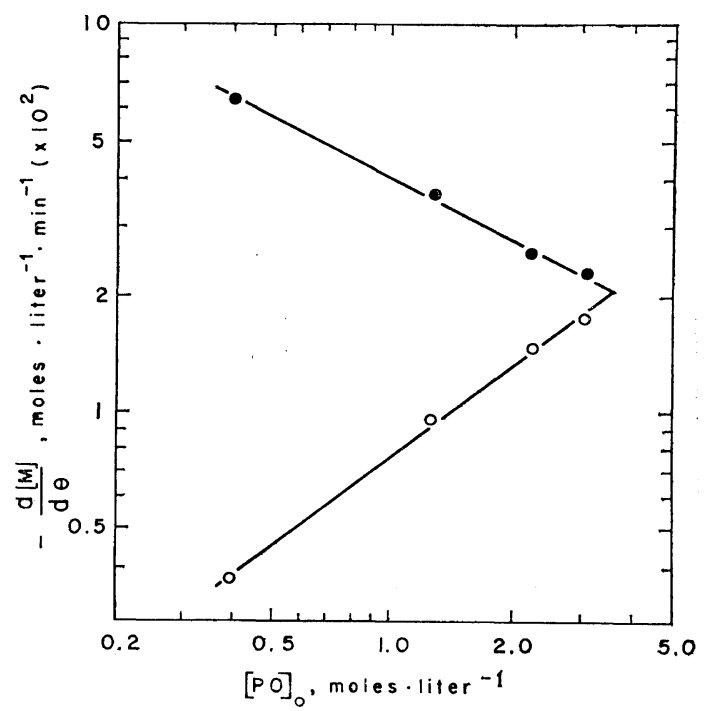

Figure 11. $\log -\log$ plots of the initial rates of comonomer consumption as a function of the initial PO concentration: $\bullet, \mathrm{d}[\mathrm{THF}]_{0} / \mathrm{d} \theta ; \bigcirc$, $\mathrm{d}[\mathrm{PO}]_{0} / \mathrm{d} \theta$. 


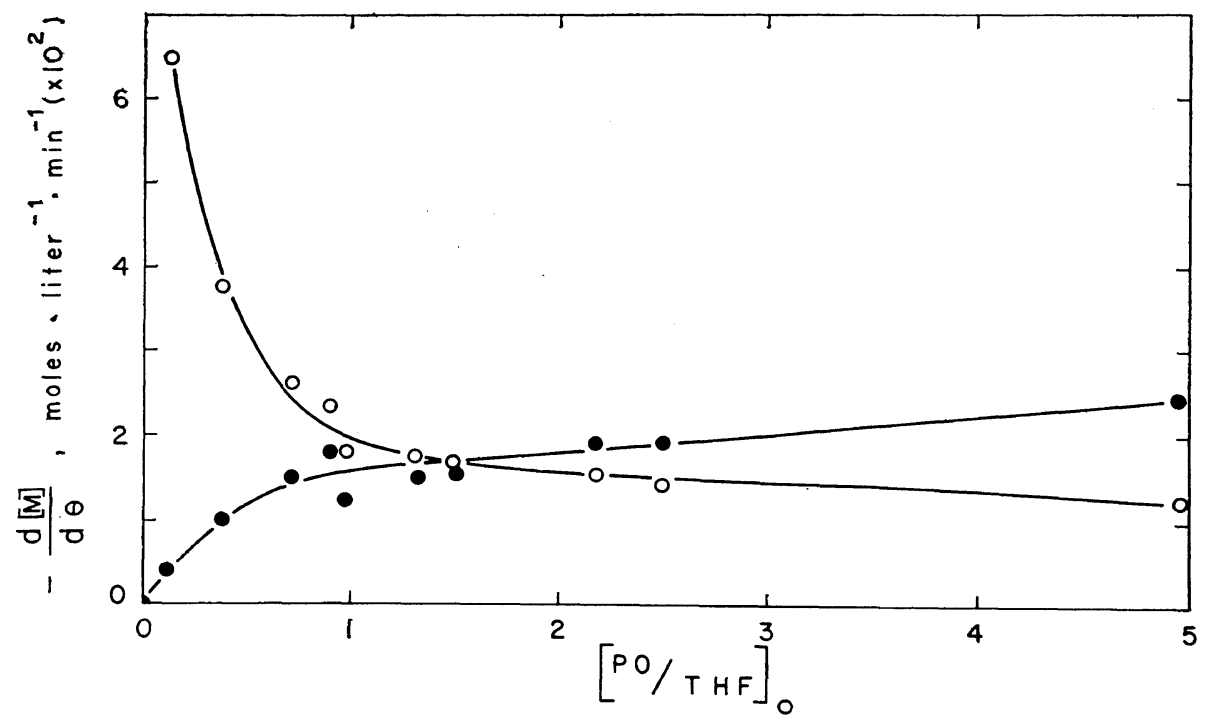

Figure 12. Variation of the initial rates of comonomer consumption as a function of $[\mathrm{PO} / \mathrm{THF}]_{0}$ molar ratio:, $\mathrm{d}[\mathrm{THF}]_{0} / \mathrm{d} \theta ; \bigcirc, \mathrm{d}[\mathrm{PO}]_{0} / \mathrm{d} \theta$.

Table VII. Variation of the molecular weights with the initial PO to THF molar ratio

\begin{tabular}{|c|c|c|c|c|}
\hline \multirow[t]{2}{*}{ No. } & \multirow[t]{2}{*}[\mathrm{PO}/\mathrm{THF}]{$_{0}$} & \multicolumn{2}{|c|}{$\begin{array}{l}\text { Comonomers } \\
\text { consumed } \\
\text { at } 300 \mathrm{~min}, \\
\mathrm{~mol} l^{-1}\end{array}$} & \multirow{2}{*}{$\begin{array}{l}\text { Molecular weight } \\
\text { of the final } \\
\text { products, } \\
\bar{M}_{n} \text { (VPO) }\end{array}$} \\
\hline & & $\Delta[\mathrm{PO}]$ & $\Delta[\mathrm{THF}]$ & \\
\hline F-5 & 0.00 & - & 0.0 & - \\
\hline F-4 & 0.12 & 0.39 & 1.06 & 283 \\
\hline F-3 & 0.38 & 1.25 & 1.64 & 660 \\
\hline $\mathrm{F}-2$ & 0.72 & 2.35 & 2.88 & 820 \\
\hline F-1 & 0.91 & 3.00 & 3.08 & 832 \\
\hline E-1 & 0.98 & 2.94 & 3.41 & 817 \\
\hline $\mathrm{E}-2$ & 1.33 & 3.10 & 2.75 & 855 \\
\hline E-3 & 1.50 & 3.02 & 2.46 & 905 \\
\hline E-4 & 2.18 & 3.63 & 1.75 & 925 \\
\hline E-5 & 2.50 & 3.52 & 1.53 & 967 \\
\hline E-6 & 4.96 & 2.73 & 0.77 & 727 \\
\hline E-7 & $\infty$ & 1.44 & - & 590 \\
\hline
\end{tabular}

comonomers indeed determine their initial rates of consumption. As can be seen from equations 5 to 8 , these rates vary directly with a positive power of the initial concentration of the monomer being changed and inversely with a different power of the unchanged comonomer. Figure 12 shows the manner in which the initial rates of comonomer consumption vary as a function of the initial molar ratio, viz. $[\mathrm{PO} / \mathrm{THF}]_{0}$. If the value of the ratio is less than 1.5, the rate of THF consumption is faster than that of PO; for ratios of 1.5 and higher, the order is reversed.

The molecular weights (see values in Table VII) of the final copolymer products show a definite trend with changing $[\mathrm{PO} / \mathrm{THF}]_{0}$ ratio. In the absence of $\mathrm{PO}$, i.e., when the $[\mathrm{PO} / \mathrm{THF}]_{0}$ ratio is zero, homopolymerization of THF does not take place. When PO is added, even in very small amounts, consumption of THF is observed. At the other extreme, when the $[\mathrm{PO} / \mathrm{THF}]_{0}$ ratio goes off to infinity, i.e., in the absence of THF, PO homopolymerizes quite easily but, as the molecular weights of the products suggest, only a low average degree of polymerization $(\overline{\mathrm{DP}} \simeq 10)$ is obtained. Between the two extremes, alternating copolymers as well as mixtures of these copolymers with homopolymers of either THF or $\mathrm{PO}$ are thought to exist. At a $[\mathrm{PO} / \mathrm{THF}]_{0}$ ratio of 0.12 , it appears that the reaction products are rich in THF homopolymer mixed with alternating copolymer and the low molecular-weight value obtained with the mixture suggests that the former must have a very low $\widehat{D P}$ value. There is a possibility that block copolymers are formed instead of THF homo- 
Cationic Copolymerization of Tetrahydrofuran with Propylene Oxide. VII.

polymers, as suggested in ref 13 . If such were the case, the blocks would necessarily be short, as indicated by the low PO reactivity ratio (0.26): THF in this case would form, at best, only 2 consecutive units along a copolymer chain. The length of the THF blocks can be calculated from results obtained during experiments carried out at the lower $[\mathrm{PO} / \mathrm{THF}]_{0}$ ratios, where homopolymerization of THF is thought to take place. If the average degree of polymerization in the homopolymer is greater than two, then the suggestion made earlier ${ }^{13}$ concerning the occurence of only 2 consecutive THF units in a polymer chain would no longer be justified. The equation

$$
\mathrm{THF}-\mathrm{THF}^{+}+\mathrm{THF} \rightarrow \mathrm{NO} \text { REACTION }
$$

suggested in this reference would then have to be discarded.

The number-average molecular weights obtained in this study vary between 700 and 1400 and the average of the values observed for $\left[M_{1}\right] /\left[M_{2}\right]$ not far removed from unity hovers around 800 . With this in mind, an attempt was made to calculate the experimental number-average molecular weight " 283 " given in Table VII from the knowledge of the $\mathrm{mol} l^{-1}$ of PO and THF consumed during a reaction, making use of the following equation:

$$
\begin{gathered}
\frac{\text { wt of copolymer }}{\bar{M}_{n} \text { (copolymer) }}+\frac{\text { wt of poly-THF }}{\bar{M}_{n} \text { (THF) }} \\
=\frac{\text { wt of [copolymer }+ \text { poly-THF] }}{\bar{M}_{n} \text { (mixture) }}
\end{gathered}
$$

For $0.39 \mathrm{~mol}^{-1} \quad$ PO consumed one requires $0.39 \mathrm{~mol} l^{-1}$ of THF to generate the alternating copolymer, leaving the remainder $\left(0.67 \mathrm{~mol} \mathrm{l}^{-1}\right.$ of THF) for the homopolymerization step. Substituting in eq 10 the weights and the molecular weights of the known quantities, one gets:

$$
\frac{50.70}{700 \text { or } 1400}+\frac{48.24}{\bar{M}_{n} \text { (THF) }}=\frac{98.94}{283}
$$

This yields an $\bar{M}_{n}$ (THF) value ranging between 155.6 and 172.3 , from which an average $\overline{D P}$ value of 2.0 is obtained. This result lends support to the data published earlier, ${ }^{13}$ in which it is suggested from NMR spectroscopic studies that when THF is in both the ultimate and penultimate positions, no further THF will add to a growing chain (eq 9).

\section{REACTIVITY RATIOS}

The reactivity ratios of any pair of comonomers, calculated by the widely accepted equation of Mayo and Lewis, ${ }^{14}$ have long been considered as a reliable index of their copolymerizability. This equation,

$$
\frac{-\mathrm{d}\left[\mathrm{M}_{1}\right]}{-\mathrm{d}\left[\mathrm{M}_{2}\right]}=\frac{\left[\mathrm{M}_{1}\right]}{\left[\mathrm{M}_{2}\right]} \cdot \frac{r_{1}\left[\mathrm{M}_{1}\right]+\left[\mathrm{M}_{2}\right]}{r_{2}\left[\mathrm{M}_{2}\right]+\left[\mathrm{M}_{1}\right]}
$$

has been transformed by some workers ${ }^{15,16}$ to the following form:

$$
\frac{-\mathrm{d}\left[\mathrm{M}_{1}\right]}{-\mathrm{d}\left[\mathrm{M}_{2}\right]}=K\left[\frac{\left[\mathrm{M}_{1}\right]}{\left[\mathrm{M}_{2}\right]}\right]^{a}
$$

were $K$ and $a$ are constants. O'Driscoll and coworkers ${ }^{17}$ have shown that, when " $a$ " is equal to or greater than zero, one can correlate " $a$ ", with the product of the reactivity ratios, $r_{1} \cdot r_{2}$.

At any two comonomer feed compositions, $x_{1}$ and $x_{2}$, where $x_{1}=\left[\mathrm{M}_{1}\right]_{1} /\left[\mathrm{M}_{2}\right]_{1}$ and $x_{2}=$ $\left[\mathrm{M}_{1}\right]_{2} /\left[\mathrm{M}_{2}\right]_{2}$, the values of $r_{1}$ and $r_{2}$ according to $\mathrm{O}^{\prime}$ Driscoll and coworkers ${ }^{17}$ may be evaluated from the following expressions:

$$
\begin{aligned}
r_{1}= & -\frac{K \cdot x_{1}{ }^{a-2} \cdot x_{2}{ }^{a-2} \cdot\left(x_{1}-x_{2}\right)}{\left(x_{1}{ }^{a-2}-x_{2}{ }^{a-2}\right)} \\
& -\frac{\left(x_{1}^{a-1}-x_{2}^{a-1}\right)}{x_{1} \cdot x_{2} \cdot\left(x_{1}{ }^{a-2}-x_{2}{ }^{a-2}\right)}
\end{aligned}
$$

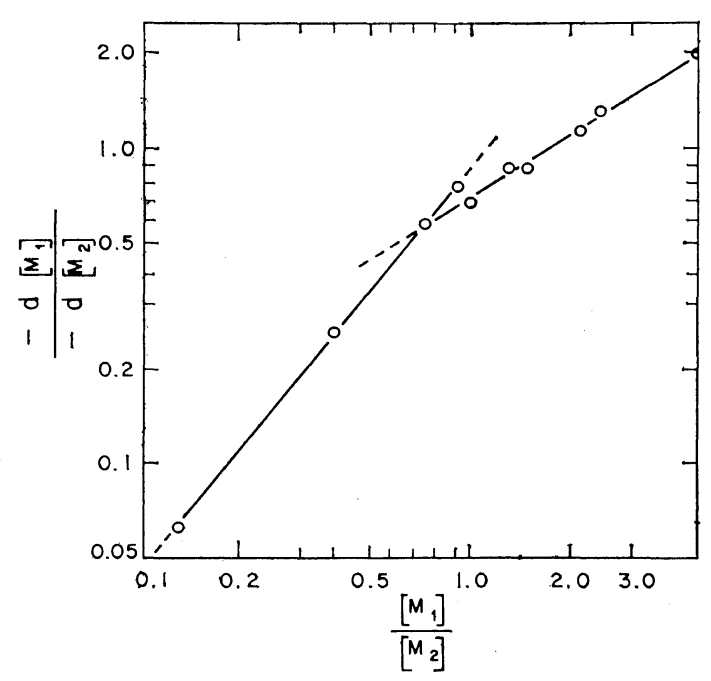

Figure 13. Log-log plot of eq 14 showing two " $a$ " values for the system, THF-PO: for PO to THF molar ratio $>1, a=0.65$; for $\mathrm{PO} / \mathrm{THF}<1$, $a=1.28$ (see Table VIII). 
Table VIII. Reactivity ratios in copolymerization reactions

\begin{tabular}{|c|c|c|c|c|c|c|c|c|c|c|c|c|}
\hline $\mathbf{M}_{1}$ & $\mathbf{M}_{2}$ & $\mathbf{M}_{1} / \mathbf{M}_{2}$ & Cat. & Cocat. & Solvent & $\underset{{ }^{\circ} \mathrm{C}}{\mathrm{Temp}}$ & $r_{1}$ & $r_{2}$ & $r_{1} r_{2}$ & $a$ & $K$ & Comments \\
\hline PO & THF & $>1$ & $\mathrm{BF}_{3}\left(\mathrm{C}_{2} \mathrm{H}_{5}\right)_{2} \mathrm{O}$ & $\mathrm{H}_{2} \mathrm{O}$ & $\left(\mathrm{CH}_{2} \mathrm{Cl}\right)_{2}$ & 0 & 0.26 & 0.80 & 0.21 & 0.65 & 0.70 & $\begin{array}{l}\text { Alternating a } \\
\text { copolymer }+\mathrm{PO} \\
\text { homopolymer }\end{array}$ \\
\hline PO & THF & $1<$ & $\mathrm{BF}_{3}\left(\mathrm{C}_{2} \mathrm{H}_{5}\right)_{2} \mathrm{O}$ & $\mathrm{H}_{2} \mathrm{O}$ & $\left(\mathrm{CH}_{2} \mathrm{Cl}\right)_{2}$ & 0 & 1.96 & 2.40 & 4.70 & 1.28 & 0.87 & $\begin{array}{l}\text { Alternating } \\
\text { copolymer+THF } \\
\text { homopolymer }\end{array}$ \\
\hline PO & THF & -1 & $\mathrm{BF}_{3} \cdot \mathrm{THF}$ & - & THF & 10 & 0.06 & 0.50 & 0.03 & 0.30 & 0.71 & $\begin{array}{l}\text { Alte } \\
\text { copo }\end{array}$ \\
\hline PO & THF & -1 & $\mathrm{BF}_{3}\left(\mathrm{C}_{2} \mathrm{H}_{5}\right)_{2} \mathrm{O}$ & $\begin{array}{l}\text { Butane } \\
\text { diol }\end{array}$ & $\left(\mathrm{CH}_{2} \mathrm{Cl}\right)_{2}$ & 0 & 0.34 & 0.63 & 0.21 & 0.66 & 0.82 & $\begin{array}{l}\text { Alte } \\
\text { copo }\end{array}$ \\
\hline PO & THF & - & $\mathrm{SbCl}_{5}$ & $\begin{array}{l}\text { 1,2 Propa- } \\
\text { ne diol }\end{array}$ & $\left(\mathrm{CH}_{2} \mathrm{Cl}\right)_{2}$ & 0 b & $\{1.0$ & 0.09 & 0.09 & 0.66 & $1.85\}$ & $\begin{array}{l}\text { Mixtures of } \\
\text { homopolymers }{ }^{10} \\
\text { and copolymers }\end{array}$ \\
\hline PO & THF & -1 & $\mathrm{BF}_{3}\left(\mathrm{C}_{2} \mathrm{H}_{5}\right)_{2} \mathrm{O}$ & $\begin{array}{l}\text { 1,2 Propa- } \\
\text { ne diol }\end{array}$ & $\left(\mathrm{CH}_{2} \mathrm{Cl}\right)_{2}$ & $0^{\mathrm{b}}$ & $\int 1.10$ & 0.08 & 0.09 & 0.62 & 2.10 & $\begin{array}{l}\text { Mixtures of } \\
\text { homopolymers }\end{array}$ \\
\hline PO & THF & -1 & $\mathrm{BF}_{3}\left(\mathrm{C}_{2} \mathrm{H}_{5}\right)_{2} \mathrm{O}$ & $\begin{array}{l}\text { 1,3 Propa- } \\
\text { ne diol }\end{array}$ & $\left(\mathrm{CH}_{2} \mathrm{Cl}\right)_{2}$ & 0 & $l_{1.0}$ & 0.09 & 0.09 & 0.65 & 1.92 & and copolymers 5 \\
\hline PO & THF & -1 & $\mathrm{BF}_{3}\left(\mathrm{C}_{2} \mathrm{H}_{5}\right)_{2} \mathrm{O}$ & $\begin{array}{l}\text { 1,2,3 Pro- } \\
\text { pane triol }\end{array}$ & $\left(\mathrm{CH}_{2} \mathrm{Cl}\right)_{2}$ & 0 & 0.85 & 0.11 & 0.09 & 0.68 & 1.66 & $\begin{array}{l}\text { Alternating } 9 \\
\text { copolymers }\end{array}$ \\
\hline PO & THF & -( & $\left(\mathrm{C}_{6} \mathrm{H}_{5}\right)_{3} \mathrm{CPF}_{6}$ & - & $\left(\mathrm{CH}_{2} \mathrm{Cl}\right)_{2}$ & 0 & 0.26 & 0.80 & 0.21 & 0.65 & 0.70 & $\begin{array}{l}\text { Alternating } 13 \\
\text { copolymers }\end{array}$ \\
\hline
\end{tabular}

a Present work.

b Values calculated with the data in ref 5, 9, and 10 using eq 12 to 15.

$$
r_{2}=-\frac{\left(x_{1}^{a-1}-x_{2}^{a-1}\right)}{\left(x_{1}^{a-2}-x_{2}^{a-2}\right)}-\frac{\left(x_{1}-x_{2}\right)}{K \cdot x_{1} \cdot x_{2} \cdot\left(x_{1}^{a-2}-x_{2}^{a-2}\right)}
$$

The constant " $a$ " can be calculated from a $\log -\log$ plot of $-\mathrm{d}\left[\mathrm{M}_{1}\right] /-\mathrm{d}\left[\mathrm{M}_{2}\right]$ as a function of $\left[\mathrm{M}_{1}\right] /\left[\mathrm{M}_{2}\right] ; K$ is obtained by setting $\left[\mathrm{M}_{1}\right] /\left[\mathrm{M}_{2}\right]$ to 1 in eq 11 :

$$
K=\frac{r_{1}+1}{r_{2}+1}
$$

Figure 13 shows a $\log -\log$ plot of $-\mathrm{d}\left[\mathrm{M}_{1}\right] /$ $-\mathrm{d}\left[\mathrm{M}_{2}\right]$ vs. $\left[\mathrm{M}_{1}\right] /\left[\mathrm{M}_{2}\right]$ based on the results obtained from the initial rates of comonomer consumption as a function of their initial concentration (Tables $\mathrm{V}$ and VI). It is obvious from the shape of the curve that different copolymeric species must be formed with different $[\mathrm{PO} / \mathrm{THF}]_{0}$ molar ratios. For ratio values of 1.0 and greater, the final copolymerization products are rich in alternating units, while for values below 1.0, dimeric THF oligomer is believed to be formed along with the alternating copolymer. These inferences have been drawn from the reactivity ratio products, $r_{1} \cdot r_{2}$, and the values of $K$ and $a$ (Table VIII) suggested in the literature. ${ }^{17}$ The values of the reactivity ratios obtained in the present study through the use of O'Driscoll's equation satisfy the Mayo-Lewis eq 11 as well, suggesting that even for such low-molecularweight copolymers the use of O'Driscoll's equation is valid.

It is apparent from the data given in Table VIII that the reactivity ratios for the copolymerization of a given pair of monomers can be different depending upon the reaction conditions adopted. It is therefore likely that the reactivity ratios $r_{1}$ and $r_{2}$ change with changing solvent, catalyst, and cocatalyst concentrations. In order to evaluate $r_{1}$ and $r_{2}$ with O'Driscoll's eq 12-15, one needs values of the initial rates of comonomer consumption for four or five different comonomer ratios. Alternatively, one may use the Mayo-Lewis eq 11 but, with two unknowns, $r_{1}$ and $r_{2}$, one can only evaluate, at best, the relative values of the reactivity ratios. This is achieved by assigning a definite value to $r_{1}$ in eq 11 and calculating the corresponding value of $r_{2}$. For each value of $r_{1}$ one obtains a correspondingly different value for $r_{2}$. Keeping in mind that the product of the reactivity ratios $r_{1} \cdot r_{2}$ for a given system is nearly a constant, 
Cationic Copolymerization of Tetrahydrofuran with Propylene Oxide. VII.

Table IX. Reactivity ratios under different reaction conditions ${ }^{a}$

\begin{tabular}{cccccc}
\hline No. & $a$ & $K$ & $r_{1}$ & $r_{2}$ & $r_{1} r_{2}$ \\
\hline A-1 & 0.59 & 0.93 & 0.41 & 0.52 & 0.213 \\
A-2 & 0.63 & 0.99 & 0.45 & 0.47 & 0.211 \\
A-3 & 0.59 & 1.03 & 0.48 & 0.44 & 0.211 \\
A-4 & 0.67 & 1.00 & 0.46 & 0.46 & 0.211 \\
A-5 & 0.64 & 0.87 & 0.37 & 0.57 & 0.211 \\
A-6 & 0.72 & 0.80 & 0.32 & 0.66 & 0.211 \\
\hline B-1 & 0.59 & 0.58 & 0.20 & 1.05 & 0.210 \\
B-2 & 0.60 & 0.60 & 0.21 & 1.00 & 0.210 \\
B-3 & 0.59 & 0.64 & 0.23 & 0.93 & 0.214 \\
B-4 & 0.60 & 0.68 & 0.25 & 0.84 & 0.210 \\
B-5 & 0.56 & 0.73 & 0.28 & 0.76 & 0.213 \\
B-6 & 0.67 & 0.76 & 0.30 & 0.70 & 0.210 \\
\hline C-1 & 0.71 & 0.64 & 0.23 & 0.91 & 0.209 \\
C-2 & 0.70 & 0.66 & 0.24 & 0.86 & 0.206 \\
C-3 & 0.71 & 0.68 & 0.25 & 0.82 & 0.205 \\
C-4 & 0.61 & 0.98 & 0.44 & 0.47 & 0.207 \\
C-5 & 0.66 & 1.00 & 0.46 & 0.45 & 0.207 \\
C-6 & 0.67 & 0.96 & 0.43 & 0.49 & 0.211
\end{tabular}

a For the conditions used in series $\mathrm{A}, \mathrm{B}$, and $\mathrm{C}$, refer to Tables I, II, and III, respectively. Constants $a$ and $K$ and reactivity ratios $r_{1}$ and $r_{2}$ have the same meaning as in Table VIII.

one can choose that set of values of $r_{1}$ and $r_{2}$ which best meets this requirement. Table IX shows the changes in reactivity ratio values with increasing concentrations of solvent, catalyst, and cocatalyst (water), with the value of the product of the reactivity ratios as 0.21 (from Table VIII for $\mathrm{M}_{1} / \mathrm{M}_{2}>1$ ). After determining the values of $r_{1}$ and $r_{2}$, those of $K$ and $a$ were computed. These values, along with those of $r_{1}$ and $r_{2}$, are presented for comparison purposes in Table IX. The first series, A-1 to A-6, shows the effect of decreasing solvent concentration on $r_{1}$ and $r_{2}$. The values of $r_{1}$ increase while those of $r_{2}$ decrease correspondingly as the ratio $[\mathrm{EC}]_{0} /[\mathrm{PO}+\mathrm{THF}]_{0}$ is changed from 1.85 to 1.38 . For values of this ratio situated between 1.38 and $0.57, r_{1}$ decreases while $r_{2}$ increases. The second series of experiments, B-1 to B-6, shows the effect of the catalyst concentration on the reactivity ratios. It is interesting to note that $r_{2}$ decreases with increasing catalyst concentration while $r_{1}$ in- creases. The reactions listed in the third series, C-1 to C-6, show the effects of the water concentration on the reactivity ratios: values of $r_{1}$ increase slightly while those of $r_{2}$ are found to decrease more rapidly up to a [water] to [cat.] ratio of nearly two. Beyond this ratio, $r_{1}$ increases abruptly from 0.25 to 0.44 and remains essentially constant thereafter, whereas $r_{2}$ changes in a similar fashion but in the opposite direction, dropping from 0.82 to 0.47 . As for the significance of the changes observed in $r_{1}$ and $r_{2}$ and the constants $a$ and $K$ for this system, with a $\left[\mathrm{M}_{1}\right]_{0} /\left[\mathrm{M}_{2}\right]_{0}$ ratio $>1$, due to variations in the concentrations of solvent (A-1 to A-6), of catalyst (B-1 to B-6), and of cocatalyst (C-1 to $\mathrm{C}-6$ ), the authors are of the opinion that these are a result most likely of changes in the nature of the active centers derived from PO-based oxonium ions.

\section{MECHANISTIC CONSIDERATIONS OF THE COPOLYMERIZATION REACTION}

Meerwein and coworkers, ${ }^{18}$ who studied the initiation of THF polymerizations with $\mathrm{BF}_{3}$ alone and in the presence of ethylene oxide (EO), reported that in the absence of EO no initiation takes place. Furthermore, they suggested that an oxonium ion mechanism is most likely responsible for the growth of the copolymer chains. Later, Kuntz, and Melchior ${ }^{19}$ in a similar study using triphenylmethyl hexachloroantimonate as catalyst also suggested the formation of oxonium salts in these polymerizations. The earlier results on the PO-THF copolymerization reported from this laboratory ${ }^{5-10,13}$ also support the concept of an oxonium ion mechanism. Based on these reports and keeping in mind that in the present study water is rapidly consumed during the early stages of the reaction and then subsequently released, the authors are led to suggest that the initiation process involves an equilibrium such as that shown below:

$$
\begin{aligned}
\left(\mathrm{C}_{2} \mathrm{H}_{5}\right)_{2} \mathrm{O}: \mathrm{BF}_{3}+\mathrm{H}_{2} \mathrm{O} & \rightleftharpoons \mathrm{H}_{2} \mathrm{O}: \mathrm{BF}_{3}+\left(\mathrm{C}_{2} \mathrm{H}_{5}\right)_{2} \mathrm{O} \\
\mathrm{H}_{2} \mathrm{O}: \mathrm{BF}_{3}+\mathrm{H}_{2} \mathrm{O} & \rightleftharpoons \mathrm{H}_{3} \mathrm{O}^{+}+\left(\mathrm{HOBF}_{3}\right)^{-} \\
\mathrm{H}_{3} \mathrm{O}^{+}+\mathrm{O} & < \\
\left(\mathrm{HOBF}_{3}\right)^{-} & \mathrm{CH}_{3}
\end{aligned}
$$




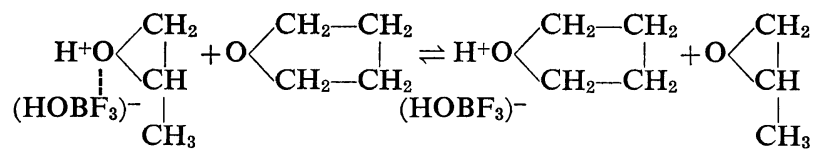

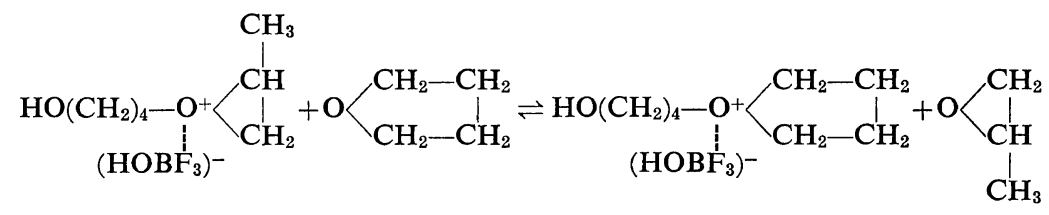

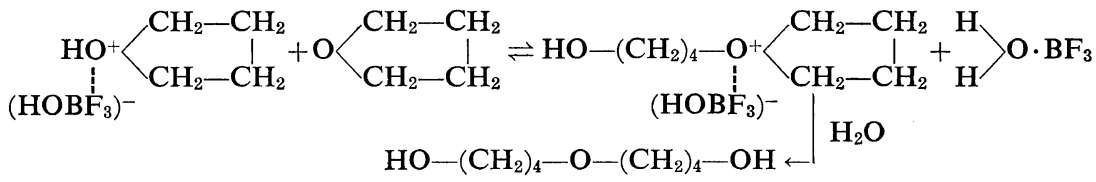

Equation 19, referred to as the most likely step leading to the initiation of THF polymerizations, must be retained to explain the fact that the homopolymerization of THF in the absence of PO does not, in fact, take place, indicating that the hydronium ion $\mathrm{H}_{3} \mathrm{O}^{+}$will not directly initiate the reaction leading to the formation of the THF

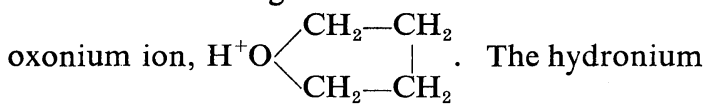
ion, on the other hand, facilitates the formation of a $\mathrm{PO}$ oxonium ion, $\mathrm{H}^{+} \mathrm{O} \underset{\mathrm{CH}}{\mathrm{C}}$ turn, by a charge transfer process, initiates the polymerization of THF via eq 19.

In an earlier study involving the copolymerization of THF and PO initiated by triphenylmethyl salts and in the presence of a diol as cocatalyst, Blanchard and coworkers ${ }^{13}$ suggested another approach based on charge transfer (eq 20): Dimeric THF oxonium ions are expected to react further with PO but not with THF (eq 9). It is difficult to say which of these mechanisms is truly responsible for the initiation step in the present study. The formation of a THF-based dimeric diol in the reaction mixture would lend support to the mechanism suggested by Blanchard and coworkers ${ }^{13}$ (eq 20); however, according to the calculations of Korovina and coworkers, ${ }^{20}$ in the absence of a diol cocatalyst this type of $r$ zaction does not occur in $\mathrm{a} \mathrm{BF}_{3}$ initiated copolymerization reaction involving THF and
PO. In the presence of water, such reactions cannot be ruled out.

Alternatively, the reaction suggested in eq 19 , where a reactive propylene oxide molecule initiates the THF polymerization by charge transfer, may indeed be a plausible one. In this case, as before, only one molecule of THF can react with the active THF species to yield dimeric THF oxonium ions, which on reacting with excess water would yield the dimeric diol $\left(\bar{M}_{n}=162\right)$, as shown in eq 21 , along with $\mathrm{H}_{2} \mathrm{O} \cdot \mathrm{BF}_{3}$.

It was mentioned earlier that if one computed $\bar{M}_{n}$ values based exclusively on a) the moles of catalyst charged initially and b) the moles of copolymer produced, one should get much higher $\overline{\mathrm{DP}}$ values than those observed in this study. The computation was carried out with the help of eq 22:

$$
\overline{\mathrm{DP}}=\frac{\text { Base-mol } / l \text { copolymer }}{[\text { catalyst }]_{0}}
$$

where $\overline{\mathrm{DP}}$ is the average degree of polymerization. The values of $\overline{\mathrm{DP}}$ in the present study do not cxceed 22 (Expt A-5). Making use of this value in combination with the initial catalyst concentration $\left(0.25 \times 10^{-2} \mathrm{~mol} l^{-1}\right)$ used, one finds that theoretically the maximum quantity of the copolymer (base-mol $l^{-1}$ ) produced should not exceed 0.055 , if all of the catalyst is attached to the ends of the growing chains prior to deactivation. In the present experiment, $1.16 \mathrm{~mol}^{-1}$ of copolymer were recovered. This would suggest that, on termination, the catalyst 
Cationic Copolymerization of Tetrahydrofuran with Propylene Oxide. VII.

is not deactivated but rather regenerated to further copolymerize comonomers, as shown in eq 21. It would appear that in order to reach such a high concentration $\left(1.16\right.$ base-mol $\left.l^{-1}\right)$ in contrast to the expected value of 0.055 , many termination steps must take place during the copolymerization process. If indeed this is the case, then the molecular-weight distribution study should yield interesting results. One would expect these to be broad or even multinodal in shape. In order to gain information about the molecular weight distribution, one has to use either the conventional methods of fraction, e.g., precipitation, or one may use gel permeation chromatography (GPC). The low molecular weights of the copolymeric species made it most difficult to use the fractionation methods. GPC analysis of the polymer samples and the separation of the low-molecular-weights oligomeric materials (as speculated on the basis of eq 10) from those of higher molecular weights could not be carried out in the present case, because of the nonavailability of this instrument at the time the study was carried out; however, recently ${ }^{13}$ similar results were obtained from the copolymerization of $\mathrm{PO}$ and THF initiated with triphenylmethyl hexafluorophosphate $\left(\mathrm{C}_{6} \mathrm{H}_{5}\right)_{3} \mathrm{C}^{+} \mathrm{PF}_{6}{ }^{-}$. The GPC analysis of each of the copolymers produced yielded binodal distributions with oligomeric materials having a $\overline{\mathrm{DP}}$ of about 5 and higher molecular weight material with $\widetilde{\mathrm{DP}}$ 's ranging between 40 and 155 .

Acknowledgments. The authors gratefully acknowledge the financial assistance received from the National Research Council of Canada, the Department of Education of the Province of Quebec, and the Defence Research Board of Canada.

The work described in this paper forms part of the general research program undertaken by the "Groupe de Recherche en Sciences Macromoléculaires" at Laval University.

\section{REFERENCES}

1. W. J. Murbach and A. Adicoff, Ind. Eng. Chem., 52, 772 (1960).

2. L. A. Dickinson, J. Polym. Sci., 58, 857 (1962).

3. T. Saegusa, H. Imai, and J. Furukawa, Makromol. Chem., 56, 55 (1962); Kogyo Kagaku Zasshi (J. Chem. Soc. Japan, Ind. Chem. Sect.), 65, 699 (1962).

4. P. R. Johnston, J. Appl. Sci., 9, 461 (1965).

5. L.-P. Blanchard, J. Singh, and M. D. Baijal, Can. J. Chem., 44, 2679 (1966).

6. M. D. Baijal and L.-P. Blanchard, in "Macromolecular Chemistry, Tokyo-Kyoto 1966" ( $J$. Polym. Sci., Part C, 23) I. Sakurada and S. Ikamura, Eds., Interscience, New York, N.Y., 1968, p 157.

7. L.-P. Blanchard and M. D. Baijal, J. Polym. Sci., Part A-1, 5, 2045 (1967).

8. L.-P. Blanchard, S. Kondo, J. Moinard, J. F. Pierson, and F. Tahiani, ibid., Part A-1, 9, 3547 (1971).

9. L.-P. Blanchard, S. Kondo, J. Moinard, J. F. Pierson, and F. Tahiani, ibid., Part $A-1,10$, 399 (1972).

10. E. J. Alvarez, V. Hornof, and L.-P. Blanchard, ibid., Part A-1, 10, 1895 (1972).

11. E. J. Alvarez, V. Hornof, and L.-P. Blanchard, ibid., Part A-1, 10, 2237 (1972).

12. J. M. Hammond, J. F. Hooper, and G. P. Robertson, ibid., Part A-1, 9, 265, 281, 295 (1971).

13. L. P. Blanchard, G. G. Gabra, V. Hornof, and S. L. Malhotra, J. Polym. Sci., Chem. Ed., 19, (1975), in press.

14. F. R. Mayo and F. M. Lewis, J. Amer. Chem. Soc., 66, 1594 (1944).

15. K. F. O'Driscoll, J. Polym. Sci., 57, 721 (1962).

16. V. Jaacks, Makromol. Chem., 105, 289 (1967).

17. T. Higashimura, T. Masuda, and K. F. O'Driscoll, J. Polym. Sci., Polym. Letters, 6, 841 (1968).

18. H. Meerwein, D. Delfs, and H. Morschell, Angew Chem., 72, 927 (1960).

19. I. Kuntz and M. T. Melchior, J. Polym. Sci., Part A-1, 7, 1959 (1969).

20. G. V. Korovina, A.I. Kuzayev, G. K. Komratov, D. D. Novikov, and S. G. Entelis, "Kinetic Mech. Polyreactions", Int. Symp. Makromol. Chem., Vol. 1, Budapest, 1969, p 287. 